\title{
Nemesia Root Hair Response to Paper Pulp Substrate for Micropropagation
}

\author{
Pascal Labrousse, ${ }^{1,2}$ David Delmail, ${ }^{3}$ Raphaël Decou, ${ }^{2}$ Michel Carlué, ${ }^{2}$ \\ Sabine Lhernould, ${ }^{2}$ and Pierre Krausz ${ }^{2}$ \\ ${ }^{1}$ Groupement de Recherche Eau, Sol, Environnement (GRESE EA4330), Laboratoire de Botanique et Cryptogamie, \\ Faculté de Pharmacie, Université de Limoges, 2 rue du Docteur Marcland, 87025 Limoges Cedex, France \\ ${ }^{2}$ Laboratoire de Chimie des Substances Naturelles (LCSN EA 1069), Faculté des Sciences et Techniques, Université de Limoges, \\ 123 Avenue Albert Thomas, 87060 Limoges Cedex, France \\ ${ }^{3}$ Laboratoire de Pharmacognosie et de Mycologie, UMR CNRS 6226 SCR, Université de Rennes 1, Equipe PNSCM, \\ 2 Avenue du Professeur Léon Bernard, 35043 Rennes Cedex, France
}

Correspondence should be addressed to Pascal Labrousse, pascal.labrousse@unilim.fr

Received 14 October 2011; Accepted 15 November 2011

Academic Editors: H. P. Bais and C. Gehring

Copyright ( $) 2012$ Pascal Labrousse et al. This is an open access article distributed under the Creative Commons Attribution License, which permits unrestricted use, distribution, and reproduction in any medium, provided the original work is properly cited.

\begin{abstract}
Agar substrates for in vitro culture are well adapted to plant micropropagation, but not to plant rooting and acclimatization. Conversely, paper-pulp-based substrates appear as potentially well adapted for in vitro culture and functional root production. To reinforce this hypothesis, this study compares in vitro development of nemesia on several substrates. Strong differences between nemesia roots growing in agar or in paper-pulp substrates were evidenced through scanning electron microscopy. Roots developed in agar have shorter hairs, larger rhizodermal cells, and less organized root caps than those growing on paper pulp. In conclusion, it should be noted that in this study, in vitro microporous substrates such as paper pulp lead to the production of similar root hairs to those found in greenhouse peat substrates. Consequently, if agar could be used for micropropagation, rooting, and plant acclimatization, enhancement could be achieved if rooting stage was performed on micro-porous substrates such as paper pulp.
\end{abstract}

\section{Introduction}

Micropropagation is a powerful biotechnology for plant multiplication $[1,2]$, but plant losses during acclimatization in greenhouse reduced, for some species, the asset of in vitro culture multiplication. In vitro rooting induction can be mediated by adding plant growth regulators or hormone-like substances to the culture medium [3]. However, the survival rate of these plants during acclimatization is low $[3,4]$. In fact, greenhouse culture conditions like hygrometry, $\mathrm{CO}_{2}$ levels, and nutrient bioavailability in culture medium are drastically different from those used for in vitro micropropagation. Most of the time, in vitro culture medium is composed of macro- and micronutrients, vitamins, carbohydrates, and eventually plant growth regulators gelified by polysaccharidic substances like agar. So, root formation in vitro could be drastically different from in classical greenhouse substrates. Gonçalves et al. [3] suggested that the lower survival rate during plant acclimatization is due to nonfunctionality of the in vitro developed rooting system. Root hairs constitute the major plant/substrate interface as they represent as much as $70 \%$ of the plant root surface $[5,6]$. So, it could be assumed that root-hair nonfunctionality can drastically reduce water and mineral nutrient uptake, thus representing a limiting key step to acclimatization in peat substrate.

As first proposed by Afreen-Zobayed et al. [4] for sweet potato, paper pulp could be a potentially suitable substrate for in vitro culture and functional root-hair production. In order to clarify this assumption, this study compares in vitro development of an ornamental plant, Nemesia denticulata (Scrophulariaceae), on several substrates like agar and paper pulp. Moreover, enhancement of nemesia acclimatization through the use of paper-pulp substrate was evaluated. 


\section{Experimental Procedures}

2.1. Preparation of Paper-Pulp Miniplugs. Paper pulp (a mixture of wood fibers from deciduous trees) was kindly provided by L. Harvengt from AFOCEL (http://www.fcba.fr/). Paper pulp was rehydrated in boiling water (200 g dry mass $\cdot \mathrm{L}^{-1}$ ) for $30 \mathrm{~min}$ and then vigorously mixed during $30 \mathrm{~min}$ in order to eliminate remaining aggregates. After supplemental water draining, paper pulp was manually pressed in plug molds $(16 \times 15 \mathrm{~mm}, \varnothing \times H)$ and dried at $50^{\circ} \mathrm{C}$ for $24 \mathrm{~h}$.

2.2. Plant Culture and Acclimatization. Nemesia denticulata (Scrophulariaceae) plants were cultivated on Murashige and Skoog's (MS) modified by Van der Salm et al. [7] medium supplemented with $20 \mathrm{~g} \cdot \mathrm{L}^{-1}$ sucrose and $7 \mathrm{~g} \cdot \mathrm{L}^{-1}$ agar HP696 (Kalys). The $\mathrm{pH}$ was adjusted to 5.8 before autoclaving at $121^{\circ} \mathrm{C}(106 \mathrm{kPa})$ for $20 \mathrm{~min}$. Cultures were maintained at $22 \pm 2{ }^{\circ} \mathrm{C}$ under fluorescent lights $\left(20 \mu \mathrm{mol} \cdot \mathrm{m}^{-2} \cdot \mathrm{s}^{-1}\right.$ of PAR light (photosynthetically active radiation), photoperiod $16 \mathrm{~h} / 24 \mathrm{~h}$ ) (Grolux 36W). After 3 subcultures, plants were placed on 4 different rooting substrates: agar $7 \mathrm{~g} \cdot \mathrm{L}^{-1}(\mathrm{~A})$, paper pulp prepared as miniplugs (PP), sorbarod (S) (cellulose plugs from Baumgartner Papiers), and peat (fertil miniplug) (P) as control. All substrates were supplemented with $5 \mathrm{~mL}$ of liquid half-strength MS Van der Salm medium. After 25 days of in vitro culture, the plants were divided into 2 batches: 24 plants per treatment were harvested and 24 other plants per treatment were then transferred to greenhouse for 21 days of acclimatization under fog (cycle of 3 min per hour, 4 times per day during 7 days). Root and shoot fresh and dry masses were measured.

2.3. Scanning Electron Microscopy. For scanning electron microscopy, 2-cm-long root tips from the apex were dehydrated in an ethanol-graded series $\left(10 \mathrm{~min}\right.$ at $10^{\circ}, 10 \mathrm{~min}$ at $30^{\circ}$, $10 \mathrm{~min}$ at $50^{\circ}, 10 \mathrm{~min}$ at $70^{\circ}, 10 \mathrm{~min}$ at $90^{\circ}$, and three $15 \mathrm{~min}$ times at $100^{\circ}$ ). After critical point drying with $\mathrm{CO}_{2}$ (FL9496 critical point dryer, Balzers Union), samples were mounted on stubs and coated with $17 \mathrm{~nm}$ of gold/paladium (SCD050 sputter coater, Baltec). Root observations were realized using a Philips XL30 scanning electron microscope at $10 \mathrm{kV}$. Root hair length was measured using Visilog Viewer 6.820 (Noesis).

2.4. Data Analysis. The data were analyzed using R.2.9.2 software. For all further statistical tests, the null hypothesis was the data normality or homogeneity, and the alpha level was set at 0.05 (data are nonnormal or heterogeneous when $P$ value $<0.05)$.

Normality of the measurement data matrix for culture was tested with multivariate Shapiro-Francia test [8] which indicates that the results are not normally distributed $(P=$ $2.649 e-05)$. Thus, only nonparametric tests will be used to process the matrix.

The experiment was laid down in a randomized complete block design. Thus, for each treatment, experiments were carried out with 24 plants and repeated in duplicate. As the data distribution was not normal, the nonparametric ANOVA Friedman test [9] was used to check if duplicates were homogenous, and no difference between duplicates was evidenced. The Friedman test [9] adapted to plant data [10] and the nonlinear principal component analysis [11] were used for medium comparisons.

\section{Results}

3.1. Scanning Electron Microscopy. Major differences in roothair morphology and length between plants growing on agar and on paper-pulp substrate (Figures 1(a) and 1(b), resp., Figure 4) were evidenced whereas roots from paper pulp and sorbarod were quite similar (Figures 1(b) and 1(d), Figure 4). It should be noted that root hairs were drastically shortened on agar in comparison with those obtained on paper-pulp substrate (Figures 1(a1), 1(a3), and 1(b1), resp., Figure 4). Moreover, root apex (epidermal cells and cap) strongly differed between the two treatments. Root cap in agar was less organized and epidermal cells were inflated and ovoid (Figure 1(a2)), whereas roots from plants cultivated on paper-pulp substrate (Figure 1(b)) presented a quiet similar morphology to roots from control plants (roots growing in greenhouse on peat substrate) which exhibited long root hairs (Figure 1(c1), Figure 4) and highly organized root cap (Figure 1(c2)).

3.2. Plant Biomass and Water Content. Plant biomass and water content were determined before and after 21 days of acclimatization (Figures 2(a) and 2(b) and Table 1). During the in vitro culture phase, no significant differences were observed between the paper pulp and agar $(P=1.000)$ and between agar and sorbarod $(P=0.317)$ even if sorbarod appeared as the best substrate for this stage in terms of biomass production (Figures 2(a) and 3). All the substrates appeared more potent for this micropropagation phase than peat $(P=0.046)$. For the acclimatization stage (Figure $2(b))$, sorbarod differed from agar $(P=4.678 e-3)$ and peat $(P=$ $0.034)$ but not from paper pulp $(P=0.479)$ which differed from peat $(P=4.678 e-3)$. Nonlinear principal component analysis (Figure 5) evidenced that paper-pulp-based substrates were the best for in vitro culture and acclimatization phase of nemesia. It should be noted that the two paper-pulp based substrates were very similar as the PC2 axis contributes only to $0.78 \%$ of the discrimination. Contrariwise, PC1 axis, contributing to $99.16 \%$ of the discrimination, clearly segregates these two media from peat and agar. Root fresh and dry masses of in vitro plants contributed, respectively, to $13.02 \%$ and $11.30 \%$ of the discrimination along the PC1 axis (Table 2). Moreover, shoot fresh mass and root dry mass of acclimatized plant contributed to $11.33 \%$ and $10.43 \%$, respectively. Along the $\mathrm{PC} 2$ axis, the main discriminant was the shoot fresh mass of the acclimatized plants $(11.56 \%)$. It could be noted that root dry mass of in vitro cultured and acclimatized plants contributed to $6.91 \%$ and $8.10 \%$ of the discrimination, respectively. For the plant water content, no significant difference could be observed between all substrates during the acclimatization phase. A slight increase in water content was evidenced in roots of in vitro nemesia from agar and peat but not in shoots. 


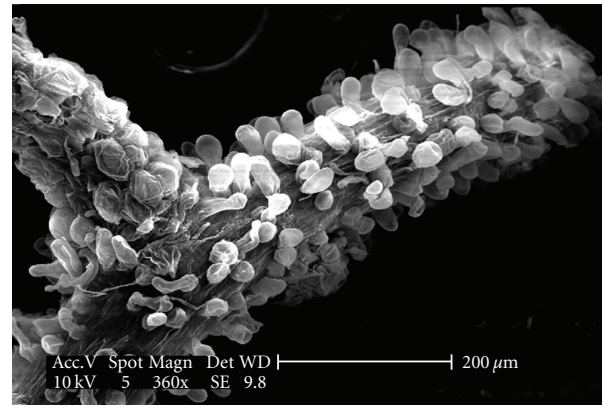

(a1)

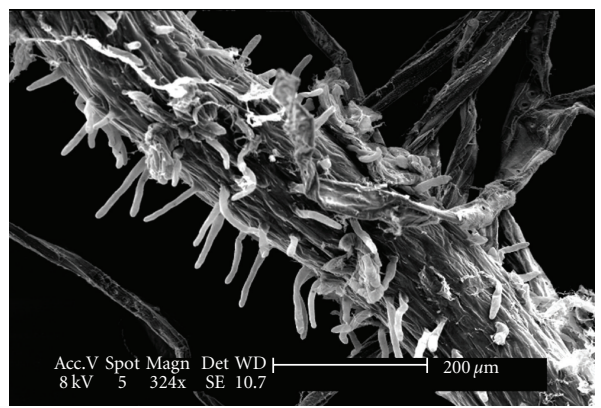

(b1)

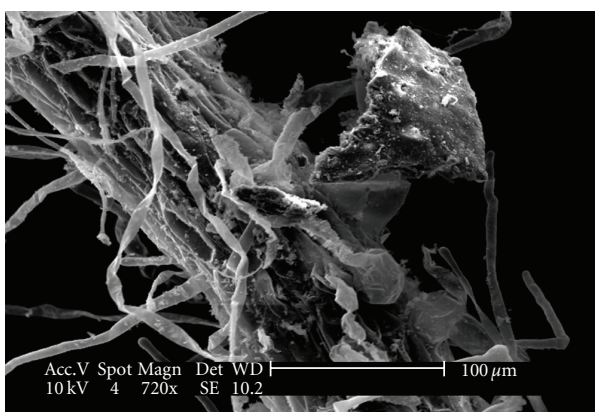

(c1)

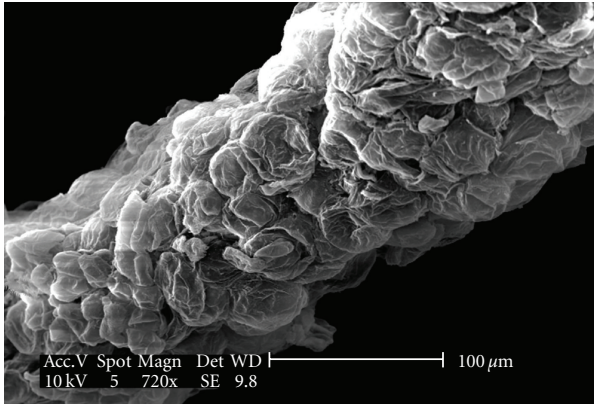

(a3)

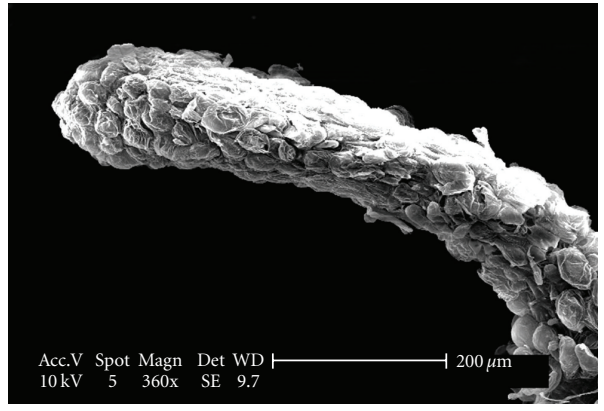

(a2)

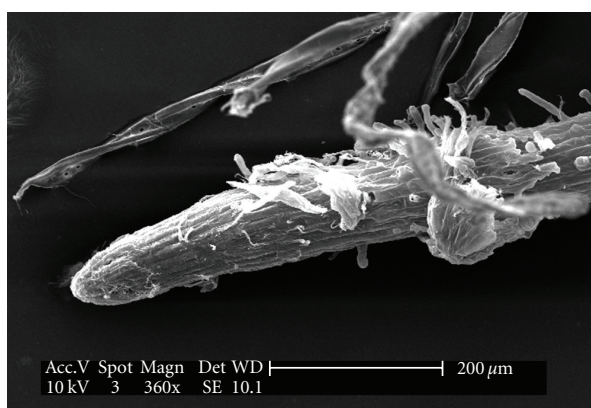

(b2)

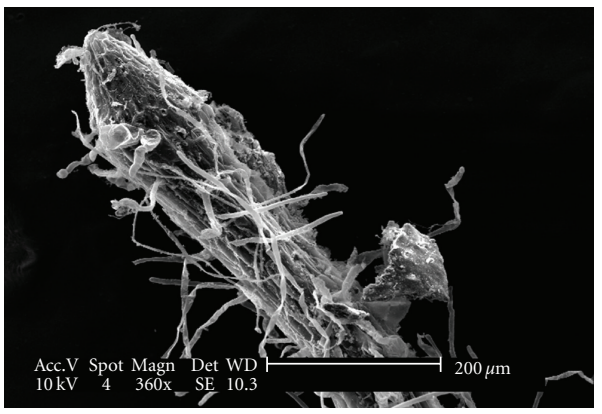

(c2)

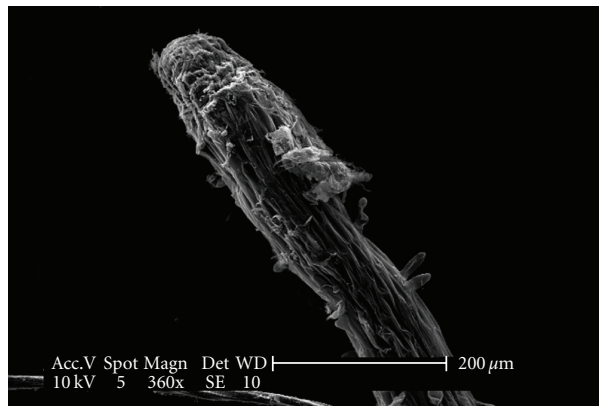

(d)

Figure 1: Nemesia roots cultivated on agar (a), paper pulp (b), and control plant (c) from greenhouse. (a1) Root hair of nemesia plant cultivated on agar medium. Note the strongly modified cellular morphology even at higher magnification in (a3). (a2) Root cap of nemesia cultivated in agar medium. No root cap is clearly identifiable. (b1) Root hair structure in nemesia root cultivated on paper pulp. (b2) Root cap of nemesia cultivated on paper pulp. Note the quiet similar structure to the control plant from greenhouse (c2). (c1) Root hair structure of the nemesia root cultivated in peat in greenhouse conditions. (c2) Root cap of nemesia cultivated in greenhouse conditions in peat. (d) Root cap of nemesia cultivated in sorbarod. 


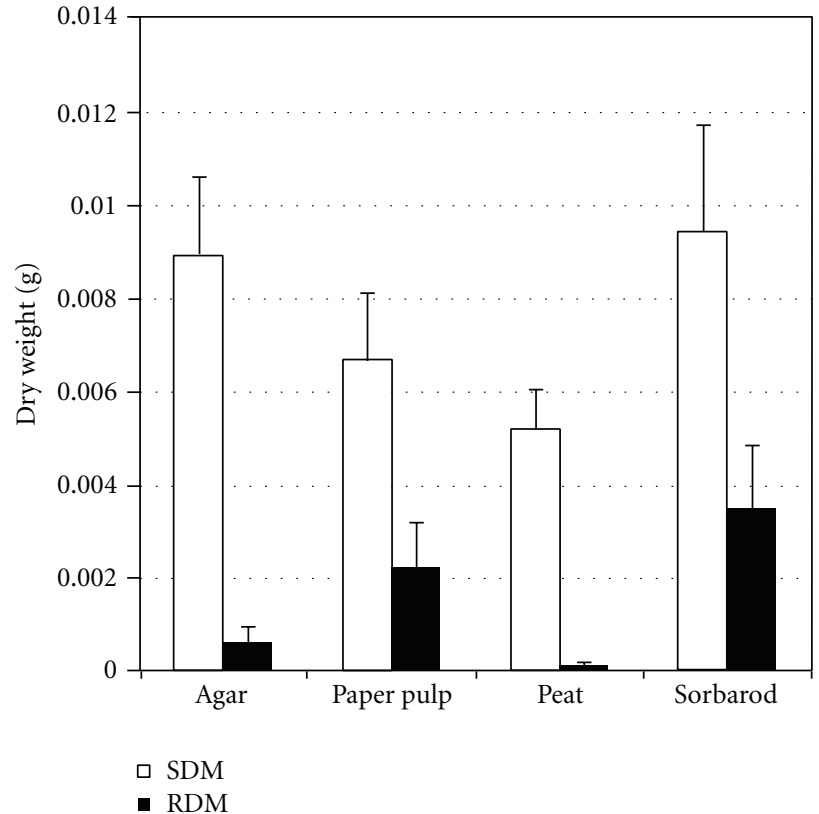

(a)

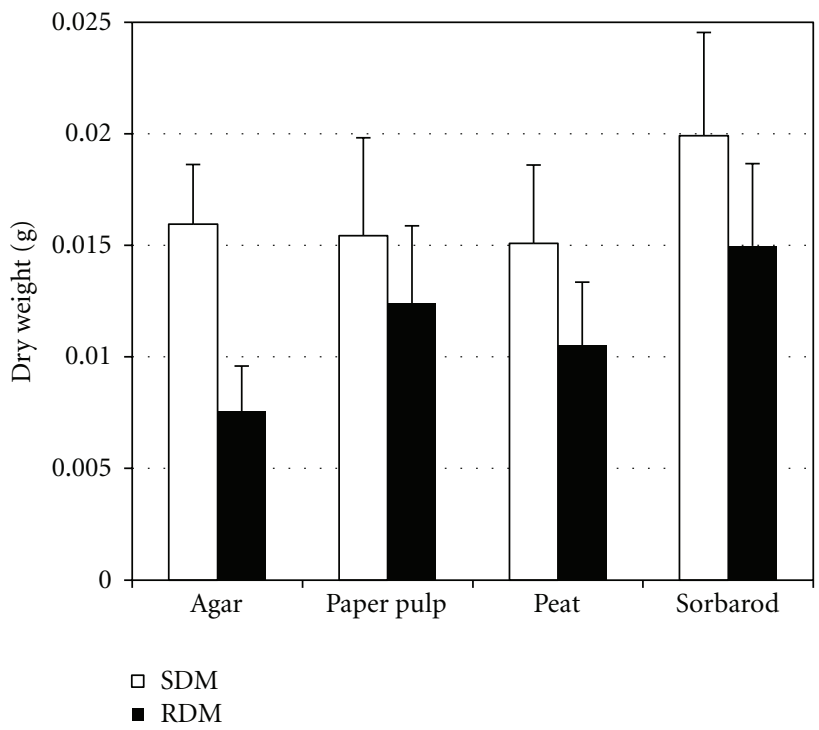

(b)

FIGURE 2: Dry mass of nemesia after 25 days of in vitro culture (a) and after 21 days of acclimatization (b). SFM: shoot fresh mass, RFM: root fresh mass, SDM: shoot dry mass, and RDM: root dry mass. Data are mean $\pm \mathrm{se}, n=24$.

TABLE 1: Nemesia water content (\%) after 25 days of in vitro culture and after 21 days of acclimatization in greenhouse conditions.

\begin{tabular}{lcccc}
\hline \multirow{2}{*}{ Water content (\%) } & \multicolumn{2}{c}{ In vitro culture } & \multicolumn{2}{c}{ Acclimatization } \\
\hline Agar & Shoot & Root & Shoot & $90.81 \pm 1.38$ \\
Paper pulp & $90.6 \pm 1.41$ & $95.36 \pm 2.40$ & $89.45 \pm 0.84$ & $90.74 \pm 1.22$ \\
Peat & $92.06 \pm 0.61$ & $88.90 \pm 1.90$ & $88.97 \pm 0.75$ & $90.05 \pm 0.99$ \\
Sorbarod & $91.36 \pm 2.15$ & $98.54 \pm 0.24$ & $87.94 \pm 0.79$ & $89.18 \pm 0.82$ \\
\hline
\end{tabular}

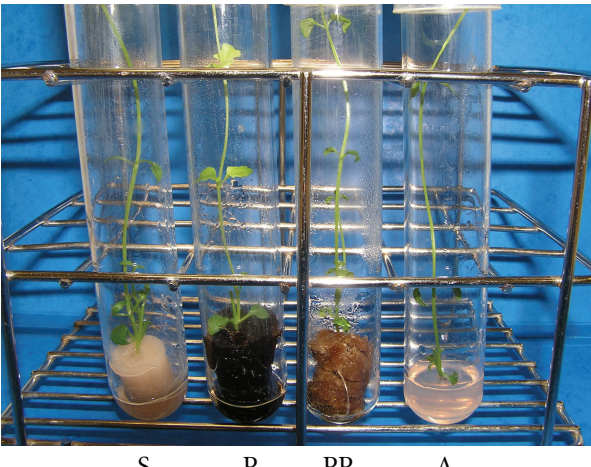

FIGURE 3: Aspect of nemesia plants on the different substrates during in vitro culture phase. S: sorbarod; P: peat; PP: paper pulp; A: agar.

\section{Discussion}

Roots of nemesia cultivated on agar medium have similar phenotype to hairless root mutants [6]. Absences of root hair and poor growth are attributed by several authors to hypoxia in agar medium $[12,13]$. In addition, Bidel et al. [14] reported that root meristems emerging from the agar gel thereafter progressed quicker than meristems remaining in the gel. These authors hypothesized the presence of several limiting factors for root growth in agar medium in addition of $\mathrm{O}_{2}$ depletion: progressive dehydration, acidification, and mineral depletion around the older root segments may also have reduced the meristem growth. Moreover, actively tip-growing root hair cells are characterized by a polarized apex rich in Golgi vesicles and mitochondria [15] suggesting important ATP needs for root-hair growth. High amounts of ATP in root hair imply a good $\mathrm{O}_{2}$ pressure in the substrate [14]. The diffusion of $\mathrm{O}_{2}$ in agar medium is lower than those found in conventional substrates. In fact, substrates other than agar, including sorbarod [16-19], foam [20-22], vermiculite [23], a vermiculite/gelrite mixture [24], peat [25], rockwool [26], coir [27], and a paper-pulp/vermiculite mixture [4], have been used to prevent low $\mathrm{O}_{2}$ pressure and poor rooting in agar medium. Decreased $\mathrm{O}_{2}$ level in a medium could be directly associated with a decrease in root-hair length and to 
TABle 2: Contribution percentage of each variable to discrimination between the four substrates along PC1 and PC2 axis in the nonlinear principal component analysis. RDM Ac: root dry mass of acclimatized nemesia; RDM C: root dry mass of in vitro cultured nemesia; RFM Ac: root fresh mass of acclimatized nemesia; RFM $\mathrm{C}$ : root fresh mass of in vitro cultured nemesia; SDM Ac: shoot dry mass of acclimatized nemesia; SDM C: shoot dry mass of in vitro cultured nemesia; SFM Ac: shoot fresh mass of acclimatized nemesia; SFM C: Shoot fresh mass of in vitro culture nemesia; TFM Ac: Total fresh mass of acclimatized nemesia; TFM C: total fresh mass of in vitro cultured nemesia; TDM Ac: total dry mass of acclimatized nemesia; TDM C: total dry mass of in vitro cultured nemesia.

\begin{tabular}{lcc}
\hline Variable & $\begin{array}{c}\text { Contribution along PC1 } \\
\text { axis }\end{array}$ & $\begin{array}{c}\text { Contribution along PC2 } \\
\text { axis }\end{array}$ \\
\hline SFM C & $0.1 \%$ & $8.23 \%$ \\
SFM Ac & $11.33 \%$ & $11.56 \%$ \\
SDM C & $2.20 \%$ & $4.99 \%$ \\
SDM Ac & $1.93 \%$ & $4.70 \%$ \\
RFM C & $13.02 \%$ & $5.19 \%$ \\
RFM Ac & $7.83 \%$ & $0.05 \%$ \\
RDM C & $11.29 \%$ & $6.91 \%$ \\
RDM Ac & $10.43 \%$ & $8.10 \%$ \\
TFM C & $0.11 \%$ & $6.57 \%$ \\
TFM Ac & $9.65 \%$ & $0.04 \%$ \\
TDM C & $2.28 \%$ & $4.39 \%$ \\
TDM Ac & $1.38 \%$ & $5.11 \%$ \\
\hline
\end{tabular}

a complementary extent with a decrease in root respiration [14]. This could result from the direct effect of redox state on gene expression as Sánchez-Fernández et al. [28] demonstrated that the redox state of cellular thiols plays a key role in root-hair growth (for an update see $[29,30]$ ). Consequences are a decrease in water, nutrient uptake, and biomass production. In a controlled and confined environment like a culture tube, plants growing on agar medium do not suffer from this poorly functional rooting system and absorb water and nutrients directly through epidermal and/or rhizodermal cells. But in greenhouse environment, atmospheric water amount is limited, and roots must assume the water and nutrient supply. Even under fog, more than 21 days of culture were necessary for tending towards a complete restoration of physiological processes. Then, the nonfunctionality of the in vitro rooting system developed in agar has no consequence on in vitro plants but has deleterious effects on plant acclimatization in greenhouse (for a review, see Hazarika [31]).

On the other hand, cheap alternatives to agar for micropropagation are currently under research from low-cost gelling agent to vegetables fibers or vegetables byproducts like Isabgol [32-35], sugarcane bagasse [36, 37], plant gums [3840], plant fibers [41-43], starch [44, 45], or other systems devoided of agar [46-52]; for a review, see Gangopadhyay et al. [53]. In this way, paper pulp could be evaluated alone or in association with compounds leading to enhance the porosity of the substrate. Similarly, Barrett-Lennard and Dracup [12] demonstrated that plant growth was increased even in po-

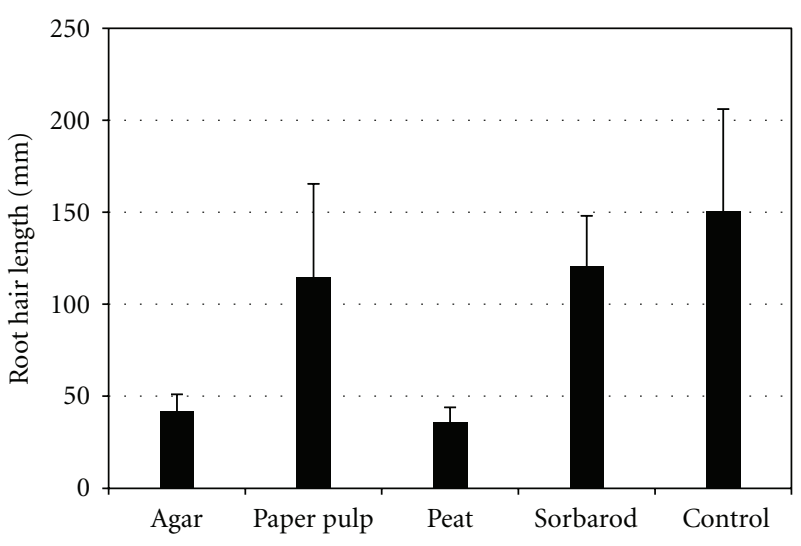

FIGURE 4: Root hair length in the different substrates in vitro. Control: root hair of the nemesia cultivated in peat in greenhouse conditions. Data are mean \pm s.e., $n=30$.

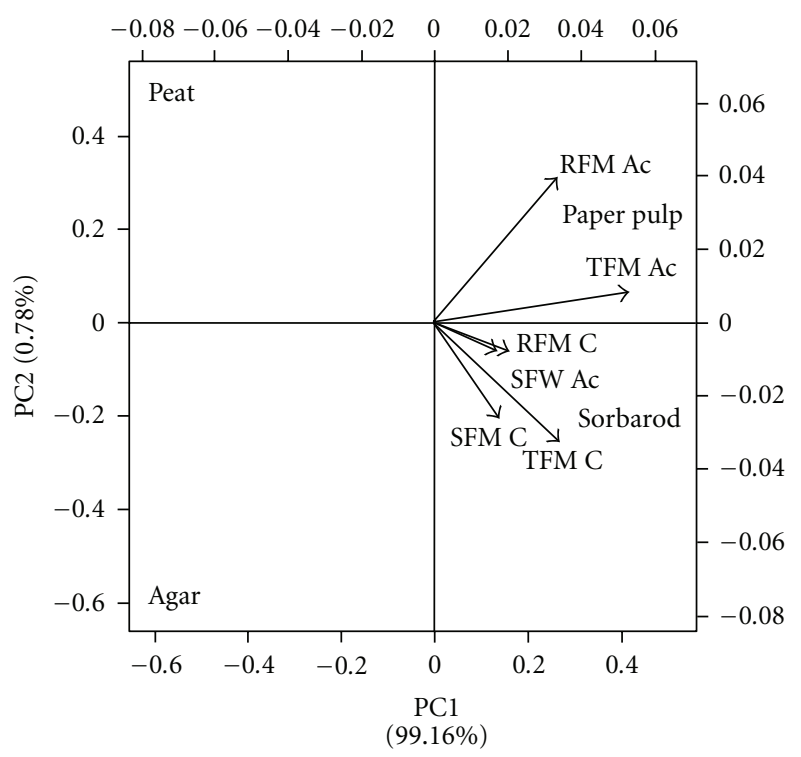

FIGURE 5: Biplot of nonlinear principal component analysis of in vitro cultured and acclimatized nemesia in the four substrates. RFM Ac: root fresh mass of acclimatized nemesia; RFM C: root fresh mass of in vitro cultured nemesia; SFM Ac: shoot fresh mass of acclimatized nemesia; SFM C: shoot fresh mass of in vitro culture nemesia; TFM Ac: total fresh mass of acclimatized nemesia; TFM C: total fresh mass of in vitro cultured nemesia. N.B.: dry masses are not visible due to high clustering near the origin.

rous agar-gelled media. Cellulose plugs like sorbarod constitute a good alternative for agar-gelled media but in the sorbarod system, plant roots pass through the pore of the plug, and only few ramifications were produced. Moreover, roots grown on filter paper matrix were often problematic to take out without injury. Paper-pulp plugs with enhanced porous structure could combine the advantages of sorbarod with a well-ramified rooting system like these obtained in paperpulp experiments.

In that sense paper, pulp appears as a good alternative to agar for rooting in vitro cultured plants before acclimatization even if a best aeration of paper-pulp miniplugs should 
be achieved in order to enhance the rooting-system development.

\section{Abbreviations}

MS: Murashige and Skoog medium.

\section{Acknowledgments}

This study was supported by a grant of Conseil Régional du Limousin and European Social Fund (ESF). Thanks were due to Pierre Carles for his help with the scanning electron microscope. Also, the authors sincerely thank Dr. Guy Costa and Dr. John Martins for critical reading of the paper.

\section{References}

[1] D. Delmail, P. Labrousse, P. Hourdin, L. Larcher, C. Moesch, and M. Botineau, "Physiological, anatomical and phenotypical effects of a cadmium stress in different-aged chlorophyllian organs of Myriophyllum alterniflorum DC (Haloragaceae)," Environmental and Experimental Botany, vol. 72, no. 2, pp. 174-181, 2011.

[2] D. Delmail, P. Labrousse, P. Hourdin, L. Larcher, C. Moesch, and M. Botineau, "Differential responses of Myriophyllum alterniflorum DC (Haloragaceae) organs to copper: physiological and developmental approaches," Hydrobiologia, vol. 664, no. 1, pp. 95-105, 2011.

[3] J. C. Gonçalves, G. Diogo, and S. Amâncio, "In vitro propagation of chestnut (Castanea sativa $\mathrm{x}$ C. crenata): effects of rooting treatments on plant survival, peroxidase activity and anatomical changes during adventitious root formation," Scientia Horticulturae, vol. 72, no. 3-4, pp. 265-275, 1998.

[4] F. Afreen-Zobayed, S. M. A. Zobayed, C. Kubota, T. Kozai, and O. Hasegawa, "A combination of vermiculite and paper pulp supporting material for the photoautotrophic micropropagation of sweet potato," Plant Science, vol. 157, no. 2, pp. 225231,2000 .

[5] R. L. Peterson and M. L. Farquhar, "Root hairs: specialized tubular cells extending root surfaces," Botanical Review, vol. 62, no. 1, pp. 1-40, 1996.

[6] J. S. Parker, A. C. Cavell, L. Dolan, K. Roberts, and C. S. Grierson, "Genetic interactions during root hair morphogenesis in Arabidopsis," Plant Cell, vol. 12, no. 10, pp. 1961-1974, 2000.

[7] T. P. M. Van der Salm, C. J. G. Van der Toorn, C. H. Hanisch ten Cate, L. A. M. Dubois, D. P. De Vries, and H. J. M. Dons, "Importance of the iron chelate formula for micropropagation of Rosa hybrida L. Moneyway," Plant Cell, Tissue and Organ Culture, vol. 37, no. 1, pp. 73-77, 1994.

[8] D. Delmail, P. Labrousse, and M. Botineau, "The most powerful multivariate normality test for plant genomics and dynamics data sets," Ecological Informatics, vol. 6, no. 2, pp. 125-126, 2011.

[9] M. Friedman, "The use of ranks to avoid the assumption of normality implicit in the analysis of variance," Journal of the American Statistical Association, vol. 32, no. 200, pp. 675-701, 1937.

[10] P. Labrousse, D. Delmail, M. C. Arnaud, and P. Thalouarn, "Mineral nutrient concentration influences sunflower infection by broomrape (Orobanche cumana)," Botany, vol. 88, no. 9, pp. 839-849, 2010.
[11] M. Scholz, F. Kaplan, C. L. Guy, J. Kopka, and J. Selbig, "Nonlinear PCA: a missing data approach," Bioinformatics, vol. 21, no. 20, pp. 3887-3895, 2005.

[12] E. G. Barrett-Lennard and M. Dracup, "A porous agar medium for improving the growth of plants under sterile conditions," Plant and Soil, vol. 108, no. 2, pp. 294-298, 1988.

[13] C. Newell, D. Growns, and J. McComb, "The influence of medium aeration on in vitro rooting of Australian plant microcuttings," Plant Cell, Tissue and Organ Culture, vol. 75, no. 2, pp. 131-142, 2003.

[14] L. P. R. Bidel, P. Renault, L. Pagès, and L. M. Rivière, "Mapping meristem respiration of Prunus persica (L.) Batsch seedlings: potential respiration of the meristems, $\mathrm{O}_{2}$ diffusional constraints and combined effects on root growth," Journal of Experimental Botany, vol. 51, no. 345, pp. 755-768, 2000.

[15] M. E. Galway, J. W. Heckman, and J. W. Schiefelbein, "Growth and ultrastructure of Arabidopsis root hairs: the rhd3 mutation alters vacuole enlargement and tip growth," Planta, vol. 201, no. 2, pp. 209-218, 1997.

[16] G. C. Douglas, C. B. Rutledge, A. D. Casey, and D. H. S. Richardson, "Micropropagation of floribunda, ground cover and miniature roses," Plant Cell, Tissue and Organ Culture, vol. 19, no. 1, pp. 55-64, 1989.

[17] M. S. Kim, N. B. Klopfenstein, and B. M. Cregg, "In vitro and ex vitro rooting of micropropagated shoots using three green ash (Fraxinus pennsylvanica) clones," New Forests, vol. 16, no. 1, pp. 43-57, 1998.

[18] A. V. Roberts, E. F. Smith, and J. Mottley, "The preparation of propagation of micropropagated plantlets for transfer to soil without acclimatization," in Methods in Molecular Biology, Vol. 6, Plant Cell and Tissue Culture, J. M. Pollard and J. M. Walker, Eds., pp. 227-236, 1990.

[19] A. V. Roberts, E. F. Smith, I. Horan, S. Walker, D. Matthews, and J. Mottely, "Stage III techniques for improving water relations and autotrophy in micropropagated plants," in Physiology, Growth and Development of Plants in Culture, P. J. Lumsden, J. R. Nicholas, and W. J. Davies, Eds., pp. 314-322, 1994.

[20] J. A. McComb and S. Newton, "Propagation of Kangaroo Paw using tissue culture," The Journal of Horticultural Science and Biotechnology, vol. 56, pp. 181-183, 1980.

[21] K. Gebhardt, "Development of a sterile cultivation system for rooting of shoot tip cultures (red raspberries) in duroplast foam," Plant Science, vol. 39, no. 2, pp. 141-148, 1985.

[22] T. D. Roche, R. D. Long, A. J. Sayegh, and M. J. Hennerty, "Commercial scale photo-autotrophic micropropagation applications in Irish agriculture, horticulture and forestry," Acta Horticulturae, vol. 440, pp. 515-520, 1996.

[23] E. Rugini and D. C. Verma, "Micropropagation of difficult to propagate almond (Prunus amygalus Batsch) cultivar," Plant Science Letters, vol. 28, pp. 273-281, 1982.

[24] C. Jay-Allemand, P. Capelli, and D. Cornu, "Root development of in vitro hybrid walnut microcuttings in a vermiculite-containing gelrite medium," Scientia Horticulturae, vol. 51, no. 34, pp. 335-342, 1992.

[25] K. Gebhardt and M. Friedrich, "Micropropagation of Calluna vulgaris cv. "H.E. Beale"', Plant Cell, Tissue and Organ Culture, vol. 9, no. 2, pp. 137-145, 1987.

[26] X. Lin, B. A. Bergann, and A. Stomp, "Effect of medium physical support, shoot length and genotype on in vitro rooting and plantlet morphology of Sweetgum," Journal of Environmental Horticulture, vol. 13, pp. 117-121, 1995. 
[27] G. Gangopadhyay, S. Das, S. K. Mitra, R. Poddar, B. K. Modak, and K. K. Mukherjee, "Enhanced rate of multiplication and rooting through the use of coir in aseptic liquid culture media," Plant Cell, Tissue and Organ Culture, vol. 68, no. 3, pp. 301-310, 2002.

[28] R. Sánchez-Fernández, M. Fricker, L. B. Corben et al., "Cell proliferation and hair tip growth in the Arabidopsis root are under mechanistically different forms of redox control," Proceedings of the National Academy of Sciences of the United States of America, vol. 94, no. 6, pp. 2745-2750, 1997.

[29] C. Gapper and L. Dolan, "Control of plant development by reactive oxygen species," Plant Physiology, vol. 141, no. 2, pp. 341-345, 2006.

[30] A. Pitzschke and H. Hirt, "Mitogen-activated protein kinases and reactive oxygen species signaling in plants," Plant Physiology, vol. 141, no. 2, pp. 351-356, 2006.

[31] B. N. Hazarika, "Morpho-physiological disorders in in vitro culture of plants," Scientia Horticulturae, vol. 108, no. 2, pp. 105-120, 2006.

[32] S. B. Babbar and N. Jain, "“Isubgol” as an alternative gelling agent in plant tissue culture media," Plant Cell Reports, vol. 17, no. 4, pp. 318-322, 1998.

[33] R. K. Tyagi, A. Agrawal, C. Mahalakshmi, Z. Hussain, and H. Tyagi, "Low-cost media for in vitro conservation of turmeric (Curcuma longa L.) and genetic stability assessment using RAPD markers," In vitro Cellular and Developmental BiologyPlant, vol. 43, no. 1, pp. 51-58, 2007.

[34] A. Agrawal, R. Sanayaima, R. Tandon, and R. K. Tyagi, "Costeffective in vitro conservation of banana using alternatives of gelling agent (isabgol) and carbon source (market sugar)," Acta Physiologiae Plantarum, vol. 32, no. 4, pp. 703-711, 2010.

[35] S. Saglam and C. Y. Cifici, "Effects of agar and isubgol on adventitous shoot regeneration of woad (Isatis tinctoria)," International Journal of Agriculture and Biology, vol. 12, no. 2, pp. 281-285, 2010.

[36] R. Mohan, C. R. Soccol, M. Quoirin, and A. Pandey, "Use of sugarcane bagasse as an alternative low-cost support material during the rooting stage of apple micropropagation," In vitro Cellular and Developmental Biology-Plant, vol. 40, no. 4, pp. 408-411, 2004.

[37] R. Mohan, E. A. Chui, L. A. Biasi, and C. R. Soccol, "Alternative in vitro propagation: use of sugarcane bagasse as a low cost support material during rooting stage of strawberry cv. Dover," Brazilian Archives of Biology and Technology, vol. 48, pp. 37-42, 2005.

[38] N. Jain and S. B. Babbar, "Gum katira-a cheap gelling agent for plant tissue culture media," Plant Cell, Tissue and Organ Culture, vol. 71, no. 3, pp. 223-229, 2002.

[39] S. B. Babbar, R. Jain, and N. Walia, "Guar gum as a gelling agent for plant tissue culture media," In vitro Cellular and Developmental Biology-Plant, vol. 41, no. 3, pp. 258-261, 2005.

[40] R. Jain and S. B. Babbar, "Xanthan gum: an economical substitute for agar in plant tissue culture media," Plant Cell Reports, vol. 25, no. 2, pp. 81-84, 2006.

[41] G. Gangopadhyay, T. Bandyopadhyay, S. B. Gangopadhyay, and K. K. Mukherjee, "Luffa sponge- a unique matrix for tissue culture of Philodendron," Current Science, vol. 86, no. 2, pp. 315-319, 2004.

[42] M. Lucchesini, A. Mensuali Sodi, S. Pacifici, and F. Tognoni, "Unconventional production of Echinacea angustifolia DC. Microplants," Acta Horticulturae, vol. 812, pp. 271-276, 2009.

[43] S. G. Dalvi, P. P. Gudhate, P. N. Tawar, and D. T. Prasad, "Low cost support matrix for potato micro-propagation," Potato Journal, vol. 38, no. 1, pp. 47-50, 2011.
[44] P. S. Naik and D. Sarkar, "Sago: an alternative cheap gelling agent for potato in vitro culture," Biologia Plantarum, vol. 44, no. 2, pp. 293-296, 2001.

[45] P. Kuria, P. Demo, A. B. Nyende, and E. M. Kahangi, "Cassava starch as an alternative cheap gelling agent for the in vitro micro-propagation of potato (Solanum tuberosum L.)," African Journal of Biotechnology, vol. 7, no. 3, pp. 301-307, 2008.

[46] A. Hoffmann, M. Pasqual, N. N.J. Chalfun, and S. S.N. Vieira, "Substrates for in vitro adventitious root induction and development on two apple rootstocks," Pesquisa Agropecuaria Brasileira, vol. 36, no. 11, pp. 1371-1379, 2001.

[47] C. Newell, D. J. Growns, and J. A. McComb, "A novel in vitro rooting method employing an aerobic medium," Australian Journal of Botany, vol. 53, no. 1, pp. 81-89, 2005.

[48] M. K. Goel, A. K. Kukreja, and S. P. S. Khanuja, "Cost-effective approaches for in vitro mass propagation of Rauwolfia serpentina Benth. Ex Kurz,' Asian Journal of Plant Sciences, vol. 6, no. 6, pp. 957-961, 2007.

[49] H. Prknová, "The use of silica sand in micropropagation of woods," Journal of Forest Science, vol. 53, no. 2, pp. 88-92, 2007.

[50] E. Bunn, "Investigations of alternative in vitro rooting methods with rare and recalcitrant plants," Acta Horticulturae, vol. 829, pp. 279-282, 2010.

[51] N. Daud, R. M. Taha, N. N. M. Noor, and H. Alimon, "Potential of alternative gelling agents in media for the in vitro micropropagation of Celosia sp," International Journal of Botany, vol. 7, no. 2, pp. 183-188, 2011.

[52] A. Sharifi, N. Moshtaghi, and A. Bagheri, "Agar alternatives for micropropagation of African violet (Saintpaulia ionantha)," African Journal of Biotechnology, vol. 9, no. 54, pp. 9199-9203, 2010.

[53] G. Gangopadhyay, S. K. Roy, and K. K. Mukherjee, "Plant response to alternative matrices for in vitro root induction," African Journal of Biotechnology, vol. 8, no. 13, pp. 2923-2928, 2009. 

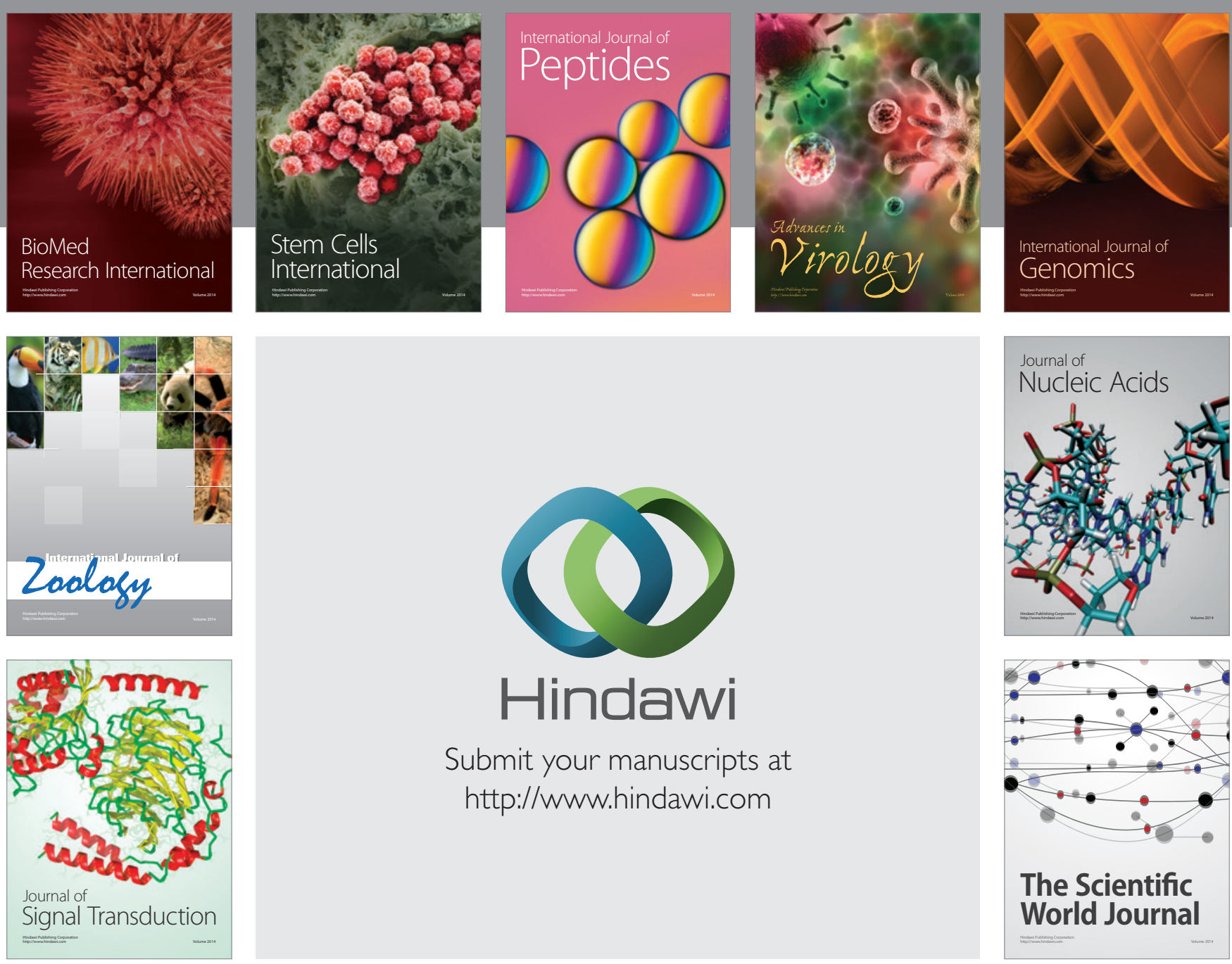

Submit your manuscripts at

http://www.hindawi.com
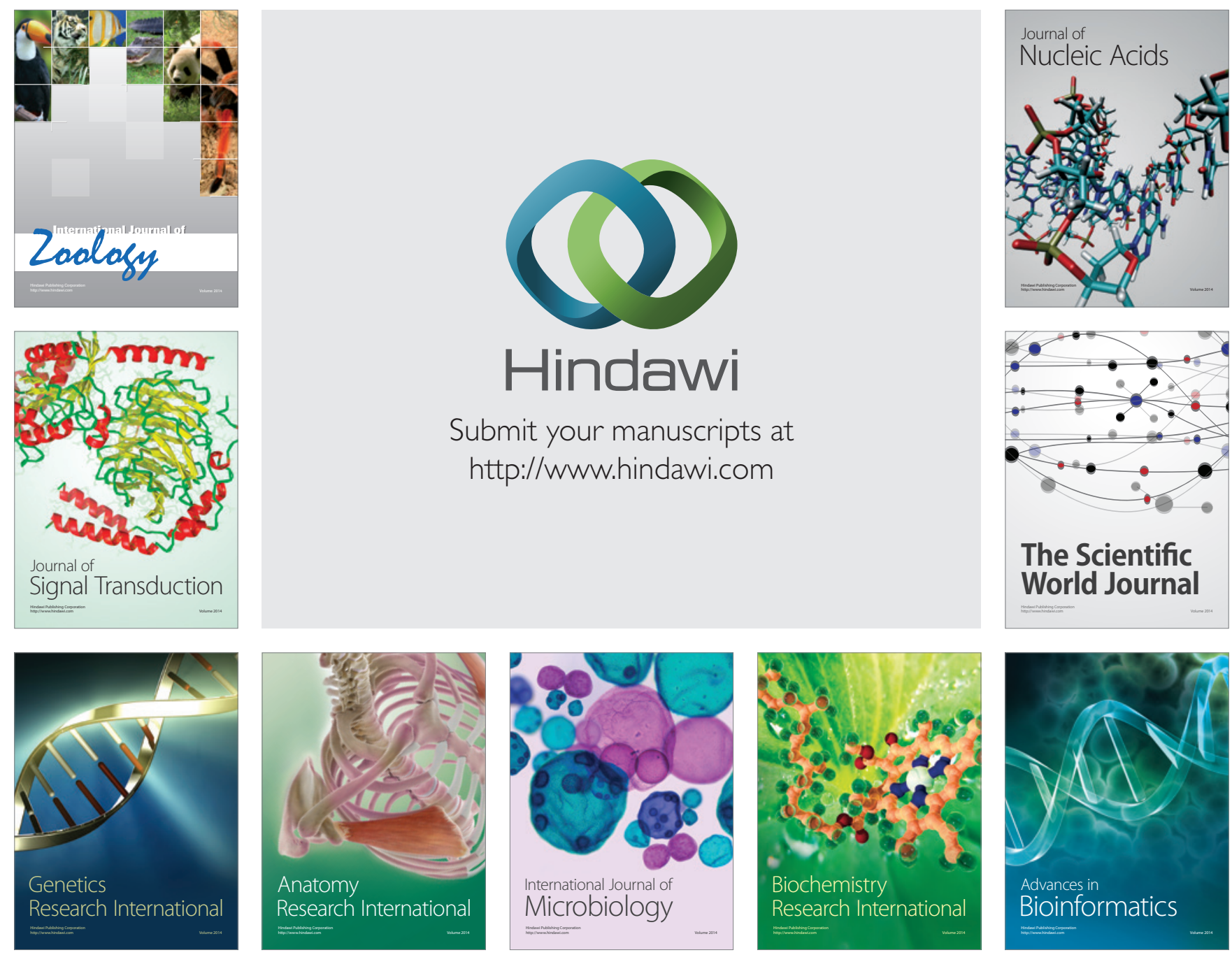

The Scientific World Journal
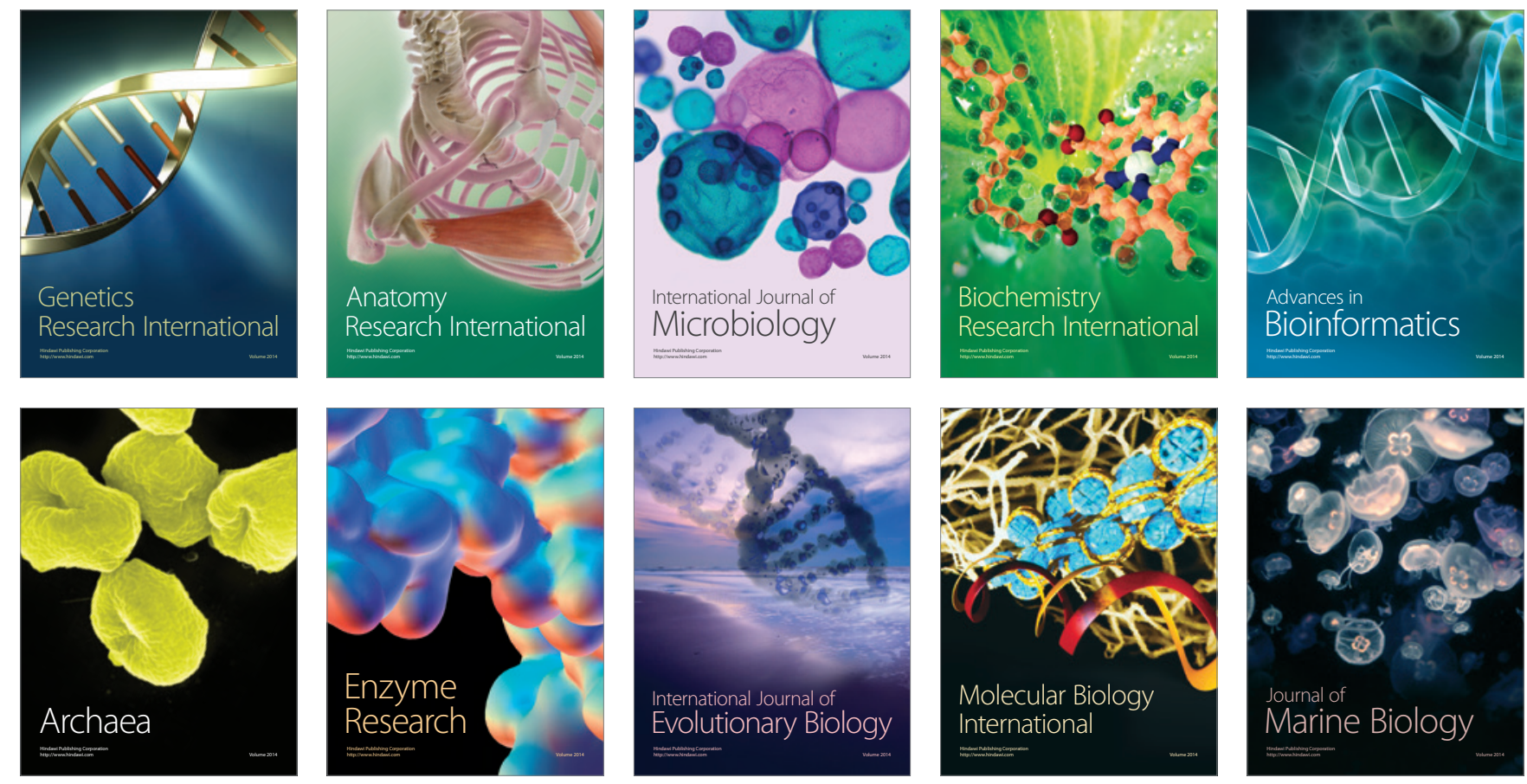